\title{
Increasing the Supply of Women Physicians in Rural Areas: Outcomes of a Medical School Rural Program
}

\author{
Howard K. Rabinowitz, MD, James J. Diamond, PhD, Fred W. Markham, MD, \\ and Abbie J. Santana, MSPH
}

Background: Women physicians are less likely then men to practice in rural areas. With women representing an increasing proportion of physicians, there is concern that this could exacerbate the rural physician shortage. The Physician Shortage Area Program (PSAP) of Jefferson Medical College (JMC) is one of a small number of medical school rural programs shown to be successful in addressing the rural physician shortage; however, little is known about their specific impact on women.

Methods: For 2394 physicians from the 1992 to 2002 JMC graduating classes, the 2007 practice location and specialty for PSAP and non-PSAP graduates were obtained from the Jefferson Longitudinal Study. The relative likelihood of PSAP versus non-PSAP graduates practicing in rural areas was determined for women and men and compared.

Results: Women PSAP graduates were more than twice as likely as non-PSAP women to practice in rural areas (31.7\% vs $12.3 \%$; relative risk, 2.6 ; 95\% CI, 1.6-4.2). This was similar to the PSAP outcomes for men $(51.8 \%$ vs $17.7 \%$; relative risk, $2.9,95 \% \mathrm{CI}, 2.2-3.9$; relative risk ratio, $0.9,95 \% \mathrm{CI}$, 0.5-1.5). PSAP outcomes were also similar for women and men practicing rural family medicine and rural primary care.

Conclusion: These results provide support that medical school rural programs have the potential to help address the serious shortage of women physicians in rural areas, thereby increasing access to care for those living there.(J Am Board Fam Med 2011;24:740-744.)

Keywords: Rural Health, Women Physicians

"The continuing preference of women for urban practice-even though less pronounced than in earlier years-may still pose a problem for the future recruitment of rural physicians. Further research must be done in this area, and programs that support women who have the potential for practic-

This article was externally peer reviewed.

Submitted 3 February 2011; revised 23 March 2011; accepted 28 March 2011.

From the Department of Family and Community Medicine, Jefferson Medical College, Thomas Jefferson University, Philadelphia, PA.

Funding: This work, as well as Drs. Rabinowitz, Diamond, and Markham and Ms. Santana, were supported in part by Health Resources and Services Administration Predoctoral Training in Primary Care grant no. D56HP08346.

Conflict of interest: none declared.

Corresponding author: Howard K. Rabinowitz, Physician Shortage Area Program, Jefferson Medical College, Thomas Jefferson University, Suite 401, 1015 Walnut Street, Philadelphia, PA 19107 (E-mail: Howard.Rabinowitz@ jefferson.edu). ing in underserved rural areas should be encouraged and supported."

-Council on Graduate Medical Education,10th Report

The shortage of physicians in rural areas represents a longstanding problem in the United States, with serious implications for access to health care. ${ }^{1-4}$ The impending expansion of health insurance resulting from the Affordable Care Act adds to the concern for the adequacy of the rural physician workforce, reinforced by the recent experience in Massachusetts. ${ }^{5}$ Another important concern regarding the future rural physician supply relates to the preference of women physicians to practice in nonrural areas compared with that of men. ${ }^{1-2,6-11}$ Combined with the dramatic increase in the proportion of women physicians in recent years, this nonrural preference by women represents a major risk to the future supply of rural physicians. In 
addition to their critical role regarding the overall supply of rural physicians, women physicians in rural areas often make special contributions compared with men physicians: they better meet the physician preferences of women patients, serve as advocates for women's health issues, and serve as female role models, although they also face unique challenges. ${ }^{12,13}$ It is critically important, therefore, to identify ways to increase the proportion of women practicing in rural areas. ${ }^{1,6,7}$

Among a number of strategies to address the overall rural physician shortage,$^{14-17}$ one of the most successful has been comprehensive medical school rural programs. These programs consist of a cohort of medical students who either have (1) been preferentially admitted based on their likelihood for rural practice and have a required rural curriculum, or (2) an extended required rural clinical curriculum. A systematic review of all six such programs with published outcomes found that more than $50 \%$ of the more than 1600 graduates over 30 years were practicing in rural areas. ${ }^{18}$ Little is known, however, regarding the specific impact of these programs on women.

The Physician Shortage Area Program (PSAP) of Jefferson Medical College (JMC) at Thomas Jefferson University is one of these medical school rural programs. ${ }^{19-21}$ The PSAP, which began in 1974 to address the rural family physician shortage in Pennsylvania, is an admissions, curricular, and mentorship program that has averaged 12 students per year. Students who grew up or lived for a substantial portion of their life in a rural area or small town and who were committed to practicing the specialty of family medicine in a similar area were invited to apply by completing a supplementary PSAP application and submitting additional letters of recommendation. During the first 2 years of medical school, students participate in individual and group faculty mentorship, clinical shadowing, and have opportunities for summer research in family medicine. During their third year, PSAP students take their required 6-week family medicine clerkship in a small town location, and in their senior year they take a family medicine subinternship, usually in a rural family medicine preceptorship. After graduation, PSAP students are expected to take a family medicine residency and practice family medicine in a rural or small town location of their choosing, although there is no mechanism to assure compliance.
The PSAP has been the most studied of all the medical school rural programs, in part because of the presence of the Jefferson Longitudinal Study of Medical Education (JLS), which has collected data on all JMC graduates since the entering class of $1968 .^{22}$ Outcomes of the first 25 JMC graduating classes (1978-2002) showed that PSAP graduates were significantly more likely to practice rural family medicine than their peers and that their longterm rural family medicine retention rate after 11 to 16 years was $79 \% .^{23-25}$

Because of the critical need to identify ways to increase the supply of rural women physicians, this study looked at the specific outcomes of the PSAP for women. It focused on graduates of more recent years (1992-2002) to better reflect the current female composition in medical schools.

\section{Methods}

As part of our ongoing longitudinal study of PSAP graduates, ${ }^{19,20,23,25}$ all PSAP graduates and their non-PSAP peers from the graduating classes of 1992 to 2002 were identified in the JLS. Data on their sex were obtained, as were their 2007 specialty and practice location. Specialty data were acquired by the JLS (2007) regarding the graduates' board certification from the American Board of Medical Specialties and their self-reported specialty from the American Medical Association Physician Masterfile. Current practice location was obtained from The Jefferson Foundation (2007), which maintains an address dataset of JMC alumni that is updated every 3 months and has been found to be highly accurate. $^{19}$ As in prior studies, office address (county) was used, ${ }^{19,20,23,25}$ and when it was unavailable we used home address county, assuming it was of similar rurality.

Similar to our previous studies, current 2007 specialty was defined as that in which the graduate was board certified. For those also certified in geriatrics, sports medicine, or adolescent medicine, their primary certified specialty was used. In all other instances, if certified in two or more specialties or not certified, then primary self-reported specialty from the American Medical Association Physician Masterfile was used. If that was also unavailable, the JMC alumni self-reported specialty was used. Graduates were considered to be practicing primary care if they were in family medicine, general internal medicine, or general pediatrics. 
Table 1. Comparison of Women and Men Physician Shortage Area Program Versus Non-Physician Shortage Area Program Graduates* Practicing in Rural Areas, Rural Family Medicine, and Rural Primary Care

\begin{tabular}{|c|c|c|c|c|c|c|c|}
\hline & \multicolumn{3}{|c|}{ Women } & \multicolumn{4}{|c|}{ Men } \\
\hline & $\begin{array}{l}\mathrm{PSAP}^{+} \\
(\mathrm{n}=41)\end{array}$ & $\begin{array}{c}\text { Non-PSAP }^{+} \\
(\mathrm{n}=707)\end{array}$ & RR (95\% CI) & $\begin{array}{l}\text { PSAP }^{\dagger} \\
(\mathrm{n}=56)\end{array}$ & $\begin{array}{c}\text { Non-PSAP }^{+} \\
(\mathrm{n}=1297)\end{array}$ & RR (95\% CI) & $\operatorname{RRR}(95 \% \mathrm{CI})$ \\
\hline Rural & $31.7(13)$ & $12.3(87)$ & $2.6(1.6-4.2)$ & $51.8(29)$ & $17.7(229)$ & $2.9(2.2-3.9)$ & $0.9(0.5-1.5)$ \\
\hline Rural Family Medicine & $26.8(11)$ & $3.7(26)$ & $7.3(3.9-13.7)$ & $35.7(20)$ & $3.0(39)$ & $11.9(7.4-19.0)$ & $0.6(0.3-1.3)$ \\
\hline Rural Primary Care & $26.8(11)$ & $6.1(43)$ & $4.4(2.5-7.9)$ & $37.5(21)$ & $4.9(64)$ & $7.6(5.0-11.5)$ & $0.6(0.3-1.2)$ \\
\hline
\end{tabular}

*Jefferson Medical College graduates, classes of 1992 to 2002.

${ }^{\dagger}$ Values shown as \% (n).

PSAP, Physician Shortage Area Program; RR, relative risk; RRR, relative risk ratio.

As in our prior study, ${ }^{25}$ graduates were considered to be practicing in a rural county if their 2007 county was designated as rural based on its ruralurban density typology. ${ }^{26}$ Graduates in all other counties were considered urban. Because there is no universally accepted definition of rural at the county level, we also used an alternate definition that we had used previously: all counties in which less than $50 \%$ of the population lived in an urbanized area (ie, a densely settled territory that contains $\geq 50,000$ people). ${ }^{19,25}$

Relative risks (RRs) and 95\% CIs were calculated comparing outcomes for PSAP versus nonPSAP graduates for both men and women. Relative risk ratios (RRRs) were calculated comparing the RR for women with that for men. In all analyses, $P<.05$ were considered to indicate statistical significance. All statistical testing was two-sided. Statistical analyses were performed using SPSS software version 16 (SPSS Inc., Chicago, IL). This study was approved by the Institutional Review Board at Thomas Jefferson University.

\section{Results}

There were 2394 JMC graduates in the classes of 1992 to 2002, including 104 PSAP graduates (4.3\%). All PSAP graduates were alive in 2007, as were 2281 of the 2290 non-PSAP graduates (99.6\%). Of the 2385 living JMC graduates, 878 $(36.8 \%)$ were women, including 43 of 104 PSAP graduates $(41.3 \%)$ and 835 of 2281 non-PSAP graduates $(36.6 \%)$. Practice specialty was available for all living graduates, and US practice location was available for 2101 of the 2385 living graduates $(88.1 \%)$, including $93.3 \%$ of living PSAP graduates (97 of 104) and $87.9 \%$ of non-PSAP graduates (2004 of 2281). Among all JMC grad- uates, women were less likely than men to practice in a rural area $(13.4 \%, 100$ of 748 vs $19.1 \%$, 258 of 1353 , respectively; RR, 0.7 ; $95 \%$ CI, $0.6-$ $0.9)$. Women were more likely than men to practice family medicine $(20.0 \%, 176$ of 878 vs $12.4 \%, 187$ of 1507 , respectively; RR, 1.6; $95 \%$ CI, 1.3-2.0) and primary care (45.7\%, 401 of 878 vs $28.6 \%, 431$ of 1507 , respectively; RR, 1.6; 95\% CI, 1.4-1.8).

Women PSAP graduates were more than twice as likely as non-PSAP women graduates to practice in rural areas (31.7\% vs $12.3 \%$; RR, 2.6; $95 \%$ CI, 1.6-4.2). This is similar to the PSAP impact on men $(51.8 \%$ vs $17.7 \%$, RR, 2.9; 95\% CI 2.2-3.9; RRR, 0.9; 95\% CI, 0.5-1.5). The positive impact of the PSAP on women and men was also similar for graduates practicing rural family medicine and rural primary care (Table 1 ).

As in prior studies, ${ }^{19,25}$ the pattern of results was similar when the secondary definition of rural (ie, counties in which less than $50 \%$ of the population lived in an urbanized area) was used throughout this study. The ratios of PSAP and non-PSAP men and women were similar, although the absolute percentages of physicians practicing in rural areas were comparably lower for all groups.

\section{Discussion}

This study showed that women PSAP graduates were more than twice as likely to practice in rural areas than women who were not in the PSAP, and this increased likelihood of PSAP women to practice rural was similar to that for men. These outcomes were also similar for women practicing rural family medicine and rural primary care. Before this comprehensive study, little information was available regarding the outcomes of medical school ru- 
ral programs on women physicians. A previous study of earlier PSAP graduates (1978-1993) found that PSAP women were equally likely to practice rural primary care as men. ${ }^{11}$ In a letter concerning 1986 to 1995 graduates from the University of Minnesota-Duluth, similar percentages of men and women graduates were reported as practicing in rural areas. ${ }^{27}$ Taken with these data, the current study provides support that medical school rural programs can substantially increase the likelihood of women practicing in rural areas.

Although this study did not address the mechanism of how the PSAP works, prior studies have provided strong evidence that the factor most important to its success is the preferential admission of medical students who are highly likely to practice in rural areas based on their rural background and future career plans. ${ }^{11,14}$ In fact, both the PSAP and University of Minnesota-Duluth share this as a core component of their programs, in addition to supporting this cohort of students during medical school with mentoring and rural curricular experiences. $^{23,28}$ Both programs have also had very high long-term rural family medicine retention rates (79\% to $87 \%) .{ }^{18}$ This suggests that identifying and preferentially admitting women who grew up in a rural area and who are committed to practicing in a rural area, along with supporting these students during medical school to help them achieve their career goals, represents an important policy for increasing the supply of rural women physicians. ${ }^{29}$ This is similar to the effect of this policy on men, and it addresses the recommendations of the Council on Graduate Medical Education and the Robert Graham Center regarding increasing the supply of women who practice in rural areas. ${ }^{1,14}$ In addition, it matches the criteria required in the new federal Rural Physician Training Grant program-part of the recently passed Affordable Care Act-that supports the development and expansion of comprehensive medical school rural programs. ${ }^{30}$

Although this study provides support for the impact of medical school rural programs on increasing the percent of women physicians practicing in rural areas, this policy itself is unlikely to resolve entirely the gender gap in rural physicians or the US rural physician shortage. As seen in Table 1, even among PSAP graduates, men are more likely than women to practice in rural areas. Nevertheless, based on the outcomes of this study (and assuming a class of 50\% women), having ap- proximately one fourth of women in the PSAP would help eliminate this rural gender gap at JMC (ie, the rural outcomes of one fourth PSAP and three fourths non-PSAP women would be similar to that of non-PSAP men). In addition, although the absolute number of physicians in the PSAP is small, our previous study showed that, if all medical schools developed (or expanded) small comprehensive medical school rural programs similar to the PSAP (with 10 students per class), the overall production of rural physicians in the United States would double. ${ }^{18}$

A limitation of this study is that it took place at one medical school. However, the large size of the study (more than 2100 graduates over 11 years), that these physicians have taken residency training in more than 343 different hospitals in 44 states and practice in 47 states, and the similar ratio of JMC men:women physicians practicing in rural areas as for the entire United States ${ }^{6}$ all support the generalizability of these outcomes. In addition, given that the PSAP has been successful in increasing the supply of women rural physicians while existing in a private medical school in the center of one of the largest metropolitan areas in the northeastern United States (characteristics associated with lower rural outcomes ${ }^{6}$ ), we believe that it is likely that this policy may have an even greater impact in medical schools in most other areas of the country.

\section{Conclusion}

This study showed that the increased likelihood of PSAP women compared with non-PSAP women practicing in rural areas was similar to that for men. This provides support that medical school rural programs have the potential to help address the serious shortage of women physicians in rural areas, thereby increasing access to care for those living there.

The authors would like to thank the Jefferson Center for Research in Medical Education and Health Care for access to the Jefferson Longitudinal Study of Medical Education; The Jefferson Foundation for access to the address files of Jefferson Medical College alumni; and the Jefferson Medical College Office of Admissions for their longstanding support of the PSAP. Finally, we offer our most important acknowledgments to the PSAP students and graduates who provide care for those living in rural areas and small towns.

\section{References}

1. Council on Graduate Medical Education. Tenth report: physician distribution and health care chal- 
lenges in rural and inner-city areas. 1998. Available at: http://www.hrsa.gov/advisorycommittees/bhpr advisory/cogme/Reports/tenthreport.pdf. Accessed 25 January 2011.

2. Rosenblatt RA. A view from the periphery: health care in rural America. N Engl J Med 2004;351: 1049-51.

3. Agency for Healthcare Research and Quality. Health care disparities in rural areas. Selected findings from the 2004 National Healthcare Disparities Report. 2005. Available at: http://www.ahrq.gov/research/ ruraldisp/ruraldispar.htm Accessed 25 January 2011.

4. Institute of Medicine Committee on the Future of Rural Health Care. Quality Through Collaboration: The Future of Rural Health. Washington, D.C.: The National Academies Press; 2005.

5. Iglehart JK. Health reform, primary care, and graduate medical education. N Engl J Med 2010;363: 584-90.

6. Rosenblatt RA, Whitcomb ME, Cullen TJ, Lishner DM, Hart LG. Which medical schools produce rural physicians? JAMA 1992;268:1559-65.

7. Colwill JM, Cultice JM. The future supply of family physicians: implications for rural America. Health Aff (Millwood) 2003;22:190-8.

8. Chen F, Fordyce M, Andes S, Hart LG. Which medical schools produce rural physicians? A 15-year update. Acad Med 2010;85:594-8.

9. Ellsbury, KE, Doescher MP, Hart LG. US medical schools and the rural family physician gender gap. Fam Med 2000;32:331-7.

10. Doescher MP, Ellsbury KE, Hart LG. The distribution of rural female generalist physicians in the United States. J Rural Health 2000;16:111-8.

11. Rabinowitz HK, Diamond JJ, Markham FW, Paynter NP. Critical factors for designing programs to increase the supply and retention of rural primary care physicians. JAMA 2001;286:1041-8.

12. Barley GE, Reeves CB, O'Brien-Gonzales A, Westfall JM. Characteristics of and issues faced by rural female family physicians. J Rural Health 2001;17: 251-8.

13. Rourke LL, Rourke J, Brown JB. Women Family physicians and rural medicine: can the grass be greener in the country? Can Fam Physician 1996;42: 1063-7.

14. Phillips RL, Dodoo MS, Petterson S, et al. Specialty and geographic distribution of the physician workforce: what influences medical student and resident choices? 2009. Available at: http://www.aafp.org/ online/etc/medialib/graham/documents/publications/ mongraphs-books/2009/rgcmo-specialty-geographic. Par.0001.File.dat/Specialty-geography-compressed. pdf. Accessed 25 January 2011.

15. Rosenblatt RA, Saunders G, Shreffler J, Pirani MJ, Larson EH, Hart LG. Beyond retention: National Health Service Corps participation and subsequent practice locations of a cohort of rural family physicians. J Am Board Fam Pract 1996;9:23-30.

16. Rosenblatt RA, Andrilla HA, Curtin T, Hart LG. Shortages of medical personnel at community health centers: implications for planned expansion. JAMA 2006;295:1042-9.

17. Rosenthal TC, McGuigan MH, Anderson G. Rural Residency tracks in family practice: graduate outcomes. Fam Med 2000;32:174-7.

18. Rabinowitz, HK, Diamond JJ, Markham FW, Wortman JR. Medical school programs to increase the rural physician supply: a systematic review and projected impact of widespread replication. Acad Med 2008;83:235-43.

19. Rabinowitz HK. Evaluation of a selective medical school admissions policy to increase the number of family physicians in rural and underserved areas. N Engl J Med 1988;319:480-6.

20. Rabinowitz HK. Recruitment, retention, and follow-up of graduates of a program to increase the number of family physicians in rural and underserved areas. N Engl J Med 1993;328:934-9.

21. Rabinowitz HK. Caring for the Country: Family Doctors in Small Rural Towns. New York: Springer-Verlag; 2004.

22. Hojat M, Gonnella JS, Veloski JJ, Erdmann JB. Jefferson Medical College longitudinal study: a prototype for evaluation of changes. Educ Health (Abingdon) 1996;9:99-113.

23. Rabinowitz HK, Diamond JJ, Markham FW, Hazelwood CE. A program to increase the number of family physicians in rural and underserved areas: impact after 22 years. JAMA 1999;281:255-60.

24. Rabinowitz HK, Diamond JJ, Markham FW, Rabinowitz C. Long-term retention of graduates from a program to increase the supply of rural family physicians. Acad Med 2005;80:728-32.

25. Rabinowitz HK, Diamond JJ, Markham, FW, Santana AJ. Increasing the supply of rural family physicians: recent outcomes from Jefferson Medical College's PSAP. Acad Med 2011;86:264-9.

26. Isserman $A M$. In the national interest: defining rural and urban correctly in research and public policy. Int Reg Sci Rev 2005;28:465-99.

27. Boulger JG. Successful Duluth PSAP narrows the gender gap [letter]. Fam Med 2001;32:6-7.

28. Boulger JG. Family medicine education and rural health: a response to present and future needs. J Rural Health 1991;7:105-15.

29. Rosenblatt R, Commentary: do medical schools have a responsibility to train physicians to meet the needs of the public? The case of persistent rural physician shortages. Acad Med 2010;85:572-4.

30. Eleventh Congress. Public Law 111-148: Patient Protection and Affordable Care Act; pp 1000-1001. Available at: http://www.gpo.gov/fdsys/pkg/PLAW111publ148/pdf/PLAW-111publ148.pdf. Accessed 25 January 2011. 